\title{
GÊNERO NO ENSINO DE CIÊNCIAS PUBLICAÇÕES EM PERIÓDICOS NO \\ BRASIL: O ESTADO DO CONHECIMENTO
}

\section{GENDER IN THE TEACHING OF SCIENCE PUBLICATIONS IN JOURNALS IN BRAZIL: THE STATE OF KNOWLDEGE}

\author{
Bettina Heerdt ${ }^{1}$ \\ Ana Paula Oliveira dos Santos ${ }^{2}$ \\ Andréa Do Carmo Bruel De Oliveira Bruel ${ }^{3}$ \\ Fernanda Mendes Ferreira ${ }^{4}$ \\ Mariane Caroline dos Anjos ${ }^{5}$ \\ Mayara Juliane Swiech ${ }^{6}$ \\ Tayna Banckes ${ }^{7}$
}

\begin{abstract}
Resumo: O artigo tem por objetivo realizar uma análise das pesquisas em Gênero e Educação Científica em todas as revistas nacionais de Ensino de Ciências e/ou Educação dos estratos A1, A2 e B1 no período de 2008 a 2018. Foram elaboradas oito unidades de registro (UR) para análise: Gênero e materiais didáticos; Gênero e inferências de interpretação; Gênero e estudos teóricos; Gênero, práticas e formação de professores; Gênero e a participação da Mulher na Ciência; Gênero e intervenções escolares; Gênero e Ciência na Mídia e Gênero e aprendizagem de Ciências, e após a análise dos artigos foi necessária à elaboração de duas UR emergentes: Interações/percepções em aulas de Ciências e Gênero e produção científica. Foram encontrados 34 artigos em 22 revistas, das 90 revistas investigadas. As pesquisas em Gênero, Ciência e Educação Científica precisam ser ampliadas e aprofundadas para que tenhamos a possibilidade de um ensino mais equânime para meninos e meninas.
\end{abstract}

Palavras-chave: Educação Científica; Gênero e Ciência; Ensino de Ciências.

Abstract: The article aims to carry out an analysis of the research on Gender and Scientific Education in all national journals of Science Teaching and/or Education of the strata A1, A2 and B1 in the period from 2008 to 2018. Eight record units (RUs) for analysis were elaborated: Gender and didactic materials; Gender and interpretation inferences ; Gender and theoretical studies; Gender, Teachers' practices and training ; Gender and the women's participation of in Science; Gender and school interventions; Gender and Science in the Media and Gender and Science Learning, and after the articles analysis it was necessary to draw up two emerging RUs: Interactions/perceptions in Science lessons and Gender and scientific production. 34

\footnotetext{
${ }^{1}$ Doutora em Ensino de Ciências e Educação Matemática. Universidade Estadual de Londrina (UEL). Docente na Universidade Estadual de Ponta Grossa (UEPG). Ponta-Grossa, Paraná, Brasil. E-mail: bettina_heerdt@yahoo.com.br

${ }^{2}$ Licencianda em Ciências Biológicas, Universidade Estadual de Ponta Grossa (UEPG). Ponta-Grossa, Paraná, Brasil. E-mail: aninha_santos1997@hotmail.com

${ }^{3}$ Mestranda em Educação, Universidade Estadual de Ponta Grossa (UEPG). Professora da Faculdade Educacional da Lapa, Lapa, Paraná, Brasil. E-mail: andreacbruel@gmail.com

${ }^{4}$ Licencianda em Ciências Biológicas, Universidade Estadual de Ponta Grossa (UEPG). Ponta-Grossa, Paraná, Brasil. E-mail: fernandamf947@gmail.com

${ }^{5}$ Mestranda em Ensino de Ciências e Educação Matemática, Universidade Estadual de Ponta Grossa (UEPG), Ponta Grossa, Paraná, Brasil. E-mail: marie.anjos@gmail.com

${ }^{6}$ Mestranda em Ensino de Ciências e Educação Matemática, Universidade Estadual de Ponta Grossa (UEPG), Ponta Grossa, Paraná, Brasil. E-mail: mayara.swiech@gmail.com

${ }^{7}$ Licencianda em Ciências Biológicas, Universidade Estadual de Ponta Grossa (UEPG). Ponta-Grossa, Paraná, Brasil. E-mail: fernandamf947@gmail.com
} 
articles were found in 22 journals of the 90 investigated journals. Papers on Gender, Science and Scientific Education must be broadened and deepened so that we have the possibility of a more equitable education for boys and girls.

Keywords: Scientific Education; Gender and Science; Science Teaching.

\section{Introdução}

A epistemologia feminista da Ciência leva em consideração a compreensão do caráter social da Ciência, que é um trabalho de homens e mulheres, como qualquer outra atividade humana, que não está à margem da sociedade, mas influencia e é influenciada pelos problemas sociais e históricos. Deste modo, o foco da discussão da epistemologia feminista é a influência de gênero nas concepções de conhecimento, em seus modos de produção e justificação, bem como na concepção de sujeito cognoscente (ANDERSON, 2011).

Na filosofia da Ciência essas discussões de gênero e Ciência têm início nos anos de 1970 quando esses termos aparecem pela primeira vez conjugados. No artigo "Qual foi o impacto do feminismo na ciência?" Keller (2006) afirma que a Ciência mudou, mesmo que, não amplamente. Para fundamentar essa afirmação, apresenta algumas mudanças na área da Biologia. Todas estão de acordo com os objetivos feministas e ocorrem devido ao maior acesso das mulheres à Ciência e ao surgimento da crítica feminista da Ciência. Londa Schiebinger (2001) escreveu um livro intitulado: $O$ feminismo mudou a Ciência? E, logo na introdução, afirma que ocorreram mudanças, e corroborando com Keller, descreve que ainda há muito a ser feito.

No Ensino de Ciências e na formação desses/as docentes as discussões epistemológicas feministas da Ciência ainda são raras. Batista et al. (2011) ao realizarem um levantamento em revistas nacionais e atas de eventos, encontraram sete artigos, num período de seis anos, destes dois tratam das representações de gênero nos livros didáticos na área de Ciências e Matemática, três apresentam representações de gênero na Ciência e dois artigos de gênero e estudos teóricos. Ao final do artigo pontuam a ausência de investigação de referenciais teórico-metodológicos, de formação docente, de produção de propostas pedagógicas no âmbito da Educação Científica.

Na pesquisa de Heerdt (2014) foi realizado um levantamento bibliográfico, em revistas nacionais e internacionais, teses, dissertações e atas de eventos, num período de 10 anos, com as palavras-chave: questões de gênero e Natureza da Ciência na formação inicial e/ou em serviço de docentes. Nesse levantamento foi observada a ausência de 
pesquisas empíricas relacionadas às noções de Ciência e às questões de gênero na Ciência e na sua construção.

Em 2017 foi realizado um levantamento em 13 periódicos nacionais e internacionais em que foi analisado o desenvolvimento das pesquisas na área de Ensino de Ciências, num período de 13 anos em relação às discussões de gênero, foram encontrados 33 artigos, 25 internacionais e oito nacionais, o que demonstra uma baixa ocorrência de pesquisas publicadas em revistas A1, A2 e B1 que são os estratos superiores do Qualis da área de Ensino, no entanto, não representam a área como um todo, mas podem dar indicativos das pesquisas (SILVA; SANTOS; HEERDT, 2017).

Destarte, foi observada a necessidade de aumentar os esforços de mapeamento da produção acadêmica, para compreender o desenvolvimento das pesquisas em gênero e Ensino de Ciências no Brasil. Assim, foram analisados todos os periódicos classificados pelo Qualis CAPES quadriênio 2013-2016 em A1, A2 e B1 nacionais da área de Ensino, para que se pudesse avaliar as lacunas e discutir os possíveis encaminhamentos para as pesquisas na área.

As questões de pesquisa que se colocam são: As questões da epistemologia feminista da Ciência estão sendo discutidas nas pesquisas de Ensino de Ciências? Quais são os focos das pesquisas relacionadas a gênero e Ensino de Ciências no Brasil? Quais as instituições de pesquisa estão produzindo conhecimentos nesta área?

\section{Referencial teórico}

A perspectiva de gênero estrutura a Ciência em diferentes níveis: na proporção de homens e mulheres na Ciência, no que e como a Ciência investiga suas prioridades e objetos escolhidos para estudo, nos conteúdos da Ciência no nível das teorias, em nomenclaturas, taxonomias, entre outros (SCHIEBINGER, 2001; FRENCH, 2009).

As mulheres na Ciência foram historicamente invisibilizadas. Não possuíam uma formação apropriada, tinham dificuldades para acessar bibliotecas, instrumentos e redes de comunicação, essas problemáticas tornam difícil para qualquer um, homens ou mulheres, empreenderem contribuições significativas para a Ciência. No entanto, sempre estiveram presentes de forma informal e anônima apoiando os homens no centro do palco (SCHIEBINGER, 2001).

A proporção de homens e mulheres na Ciência em algumas áreas ainda é desproporcional nos dias atuais. Desde 1960 o número de diplomadas em bacharéis de 
Ciência tem aumentado, entretanto, enfrentam barreiras ao entrarem na carreira científica e para obter sucesso em tais carreiras, "mulheres com altas posições na academia, por exemplo, diminui drasticamente na medida em que subimos na escada em direção as posições dos titulares" (FRENCH, 2009, p. 140), o denominado "teto de vidro" uma barreira supostamente invisível que impede as mulheres de atingirem o topo (SCHIEBINGER, 2001).

O que a Ciência pesquisa pode ser determinada ou pelo menos influenciada por gênero. French (2009) cita como exemplo o caso dos estudos da contracepção que tem se centrado no âmbito feminino. A ideia socialmente imposta da responsabilidade quase que exclusiva das mulheres para com a gravidez e os cuidados com os/as filhos/as foi reafirmada pela Ciência ao produzir 13 métodos contraceptivos à disposição atualmente, apenas três são direcionados aos homens, todos os demais deixam a responsabilidade para a mulher. Outra questão é como os efeitos colaterais e os testes de anticoncepcionais femininos têm sido divulgados e tratados é indicativo de alguma parcialidade de gênero.

Gênero pode determinar como a Ciência investiga. Nas Ciências Biológicas o rato macho é tido como norma extensiva a outras espécies, inclusive a humana, e a fêmea rata como desvio da norma. Os pesquisadores podem dizer que não existe parcialidade de gênero, "poderão argumentar que os ratos machos são melhores de lidar, por exemplo, não ficam grávidos e não estão sujeitos as mesmas mudanças hormonais". (FRENCH, 2009, p. 142).

$\mathrm{Na}$ área de medicina, as pesquisas e tratamentos médicos utilizavam como modelo um homem branco, com 75 quilos. As mulheres apareciam nos livros de medicina somente nas seções relacionadas à reprodução e as partes não reprodutivas se concentravam no corpo masculino. Esse modelo trouxe diversos prejuízos no tratamento das mulheres (SCHIEBINGER, 2001).

Gênero no conhecimento científico, um viés de gênero, muitas vezes, é expresso na descrição dos dados, em premissas e hipóteses de pesquisa sexistas ou androcêntricas, incorporado a um fazer científico pretensamente neutro. Essas pesquisas conferem cientificidade à inferioridade intelectual da mulher e justificam seu papel subordinado na sociedade. As investigações dos hormônios é um dos exemplos, as ideias culturais naturalizadas de gênero ficaram evidentes, pois esperavam estabelecer que cada sexo teria seu hormônio específico e definido (FAUSTO-STERLING, 2000).

Outra questão é a da evolução humana, hoje temos duas hipóteses explicativas aprimeira é centrada no Manhunter, o homem caçador e seu papel crucial na evolução 
dos seres humanos para a forma que hoje conhecemos. A interpretação dos dados foi elaborada por meio da observação de pedras lascadas, que foram então tomadas como evidência inequívoca de caça. Assim foi inferido que os machos são centrais não apenas para a evolução da espécie, mas para a sobrevivência dos membros de um grupo.

Esse cenário foi consistente com o homem branco, cultura que dominava círculos científicos até os anos 60 e início dos anos 70. A segunda hipótese foi desenvolvida quando o movimento feminista ficou mais forte, as mulheres reivindicaram o reconhecimento nas várias disciplinas científicas e a história da evolução dos hominídeos começou a mudar. Uma história que é mais consistente com uma abordagem feminista é centrada na mulher coletora e seu papel central na evolução dos seres humanos (LONGINO; DOELL, 1983; ABD-EL-KHALIC; BELL; LEDERMAN, 1998). Essas duas explicações nos permitem perceber a natureza epistemológica arbitrária da Ciência. As duas hipóteses são alvos de críticas, uma vez que mantêm os dualismos.

Nesses exemplos, e em tantos outros, podemos observar as questões de gênero influenciando na dinâmica do desenvolvimento da Ciência. Esses conhecimentos não apareceram por acaso, a epistemologia feminista proporcionou à Ciência um novo olhar, novos valores, que foram produzidos tanto por mulheres quanto por homens. Essas discussões precisam estar presentes no Ensino de Ciências para que seja possível uma Ciência e um ensino mais equânime.

\section{Procedimentos metodológicos}

Este estudo está inserido no âmbito de pesquisa qualitativa. Para a coleta de dados foi utilizada a Plataforma Sucupira na qual foram selecionadas todas as revistas nacionais avaliadas no Qualis capes quadriênio 2013-2016 na área de Ensino classificadas em A1, A2 e B1. Os artigos foram selecionados por meio dos títulos, resumos e palavras-chave que continham os termos relacionados a Gênero e Ciência no ensino de Ciências, Biologia, Física, Química e/ou Matemática e/ou Educação Científica. Após a leitura dos artigos aqueles que apesar de conter a palavra gênero no título, palavras chave e/ou resumo tinham o foco nas discussões de sexualidade e identidade sexual não foram analisados. A pesquisa foi realizada num período de 10 anos (2008a 2018). Foram investigadas 90revistas (apêndice 01). 
Para a análise dos artigos foram organizadas unidades de registro (UR) (BARDIN, 2004). Foram utilizadas as unidades propostas por Batista et al., (2011) e Silva, Santos e Heerdt (2017), algumas com adaptações (quadro 01).

\begin{tabular}{|c|c|}
\hline Unidades de Registro & Descrição \\
\hline UR 1. Gênero e materiais didáticos. & $\begin{array}{l}\text { Os artigos classificados nesta unidade analisam como ocorrem } \\
\text { as representações de gênero nos livros didáticos (BATISTA et } \\
\text { al., 2011). }\end{array}$ \\
\hline $\begin{array}{l}\text { UR 2. Gênero e inferências de } \\
\text { interpretação }\end{array}$ & $\begin{array}{l}\text { Os artigos classificados nesta unidade estudam o interesse de } \\
\text { meninas e meninos pela Ciência e suas relações/percepções da } \\
\text { Ciência em cursos de nível médio, técnico e superior de ensino } \\
\text { (BATISTA et al., 2011, adaptado). }\end{array}$ \\
\hline UR 3. Gênero e estudos teóricos & $\begin{array}{l}\text { Os artigos classificados nesta unidade apresentam uma revisão } \\
\text { teórica sobre a necessidade da incorporação das questões de } \\
\text { gênero nas investigações em Educação em Ciências e } \\
\text { Matemática (BATISTA et al., 2011). }\end{array}$ \\
\hline $\begin{array}{l}\text { UR 4. Gênero, práticas e formação } \\
\text { docente. }\end{array}$ & $\begin{array}{l}\text { Os artigos classificados nesta unidade analisam as noções e a } \\
\text { formação docente acerca das questões de gênero (SILVA, } \\
\text { SANTOS, HEERDT, 2017). }\end{array}$ \\
\hline $\begin{array}{l}\text { UR 5. Gênero e a participação de } \\
\text { Mulheres na Ciência. }\end{array}$ & $\begin{array}{l}\text { Os artigos classificados nesta unidade analisam à participação } \\
\text { das mulheres na história e na atualidade da Ciência (SILVA, } \\
\text { SANTOS, HEERDT, 2017). }\end{array}$ \\
\hline UR 6. Gênero e Intervenções. & $\begin{array}{l}\text { Os artigos classificados nesta unidade apresentam abordagens } \\
\text { metodológicas que levem em consideração as questões de } \\
\text { gênero no ensino (SILVA, SANTOS, HEERDT, 2017, } \\
\text { adaptado). }\end{array}$ \\
\hline UR 7. Gênero e Ciência na Mídia. & $\begin{array}{l}\text { Os artigos classificados nesta unidade analisam como questões } \\
\text { de gênero e Ciência são abordadas em diferentes mídias } \\
\text { (SILVA, SANTOS, HEERDT, 2017). }\end{array}$ \\
\hline $\begin{array}{l}\text { UR 8. Gênero e aprendizagem de } \\
\text { Ciências. }\end{array}$ & $\begin{array}{l}\text { Os artigos classificados nesta unidade analisam as diferenças } \\
\text { entre homens e mulheres no processo de aprendizagem da } \\
\text { Ciência (SILVA, SANTOS, HEERDT, 2017). }\end{array}$ \\
\hline $\begin{array}{l}\text { URE 9. Interações/percepções em } \\
\text { aulas de Ciências. }\end{array}$ & $\begin{array}{l}\text { Os artigos classificados nesta unidade apresentam diferenças de } \\
\text { interações/percepções entre docentes e estudantes, meninas e } \\
\text { meninos nas aulas de Ciências. }\end{array}$ \\
\hline $\begin{array}{l}\text { URE 10. Gênero e produção } \\
\text { científica. }\end{array}$ & $\begin{array}{l}\text { Os artigos classificados nesta unidade apresentam analises da } \\
\text { produção científica nacional e/ou internacional em relação a } \\
\text { gênero. }\end{array}$ \\
\hline
\end{tabular}

Quadro 1: Unidades de Registro e suas descrições.

Fonte: autoras (2018).

\section{Resultados e discussões}

A partir do mapeamento foram analisadas 90 revistas nacionais (apêndice 01) de Ensino de Ciências e Educação, classificadas em A1, A2 e B1, destas em 22 revistas foram encontrados 34artigos (figura 1). 


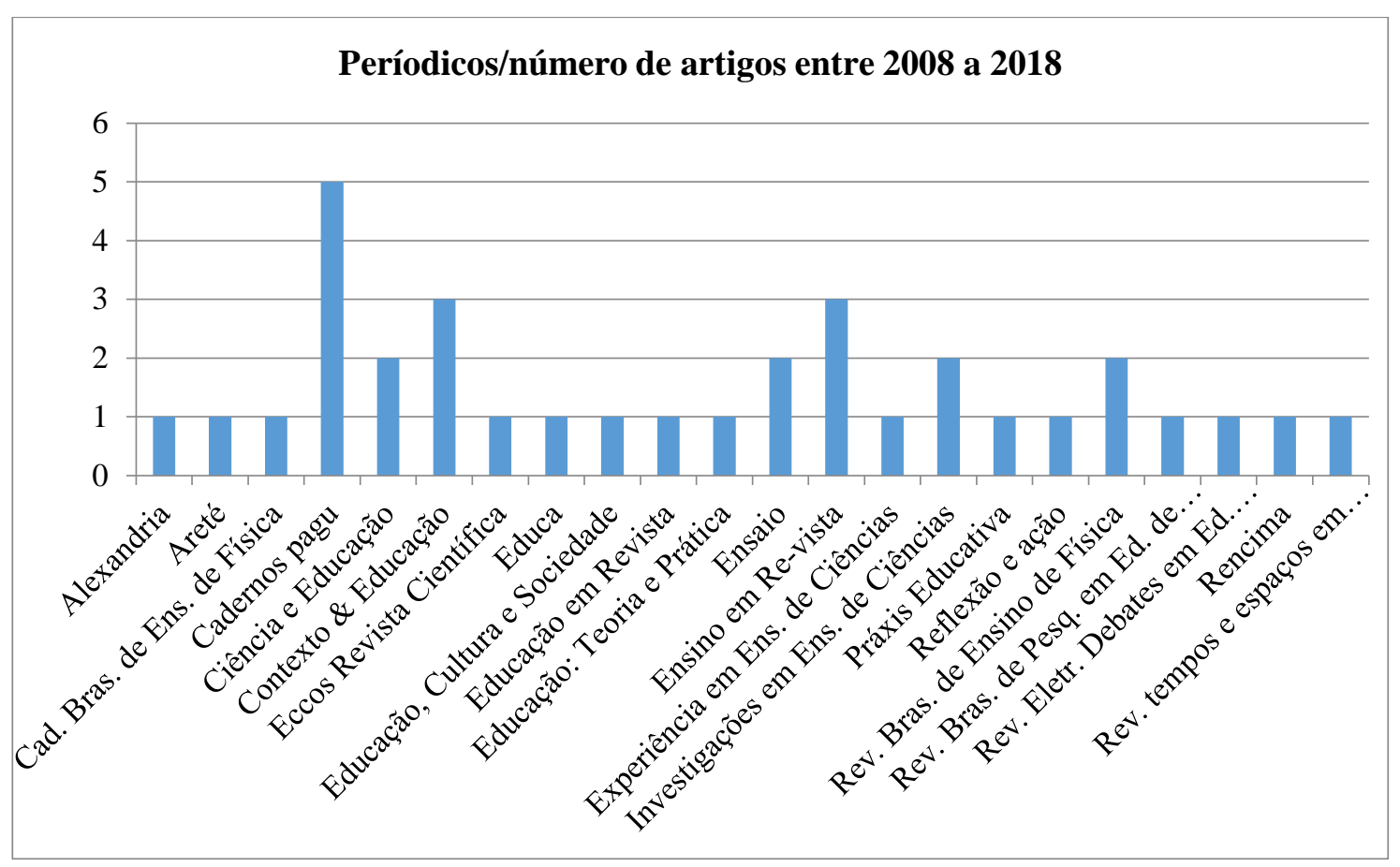

Figura 1: Periódicos científicos e o número de artigos encontrados em relação a temática gênero na Educação Científica.

Fonte: Autoras (2018).

A maioria das revistas possui uma única publicação que envolve a temática de gênero na Educação Científica. A revista Cadernos Pagu que tem como objetivo contribuir para a ampliação e fortalecimento do campo interdisciplinar de estudos de gênero no Brasil é o que apresenta o maior número de publicações no período, o que se justifica por ser um periódico com foco em estudos de gênero. Ao comparar esse estudo com o de Silva, Santos e Heerdt (2017) percebe-se que a ampliação dos esforços no mapeamento foi significativa, de oito encontrados anteriormente o número se elevou para 34 artigos, ainda que as pesquisas realizadas foram somente nos estratos superiores da qualis/capes da área de Ensino e não representam o todo, mas possibilitam um forte indicativo das pesquisas na área no Brasil.

Nas revistas brasileiras analisadas não foi encontrada nenhuma edição especial dedicada a mulheres, gênero e Ensino de Ciências. Em revistas internacionais isso já ocorre, a exemplo da Science \& Education em que há número especial com o título: Introduction: Women, Science Education and Feminist Theory, organizado pela pesquisadora Cassandra L. Pinnick em 2008, que conta com oito artigos que discutem a mulher na Ciência, as questões de gênero na Educação Científica e as teorias feministas.

Quanto ao número de artigos publicados entre 2008 e 2018nas revistas nacionais analisadas pode-se observar um crescimento (Figura 2). 


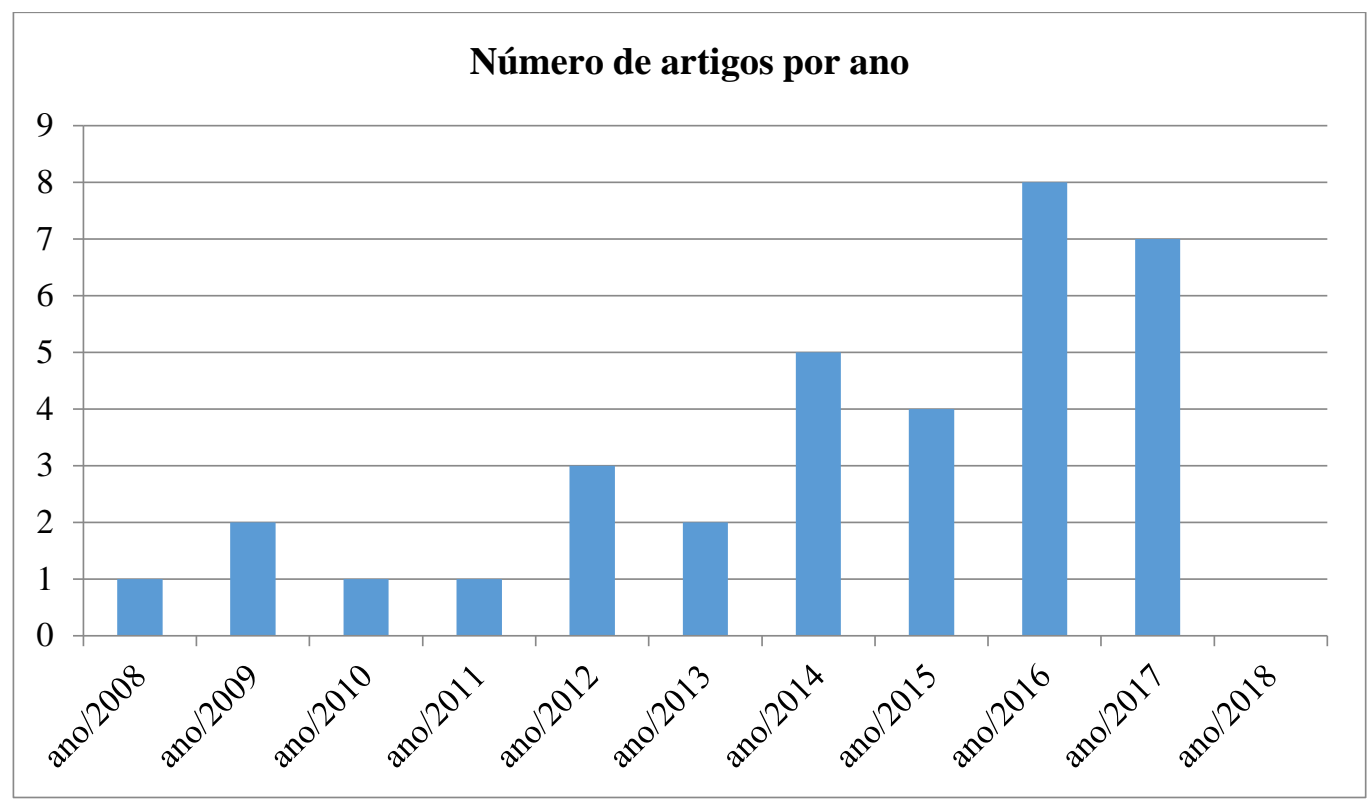

Figura 2: Número de artigos por ano em relação à temática gênero na Educação Científica. Fonte: Autoras (2018).

Nos últimos anos (2014 a 2017) há uma tendência de crescimento de publicações, com exceção de 2018, mas justifica-se que a maioria das revistas, até o momento, só possui a primeira edição.

A análise das instituições e do número de pesquisadoras/es possibilitou identificar as predominâncias regionais, de instituições e de homens e mulheres que impulsionam e fomentam a discussão de gênero na Educação Científica (Figura 3).



Figura 3: Instituições acadêmicas e pesquisadores/as que publicaram trabalhos em Gênero, Ciência e Educação Científica.

Fonte: Autoras (2018). 
No que diz respeito às instituições acadêmicas temos 29 no total, sendo que 21 são instituições brasileiras e destas $67 \%$ são da região sul e sudeste e oito internacionais (Argentina, Alemanha, México, Estados Unidos, Espanha, Chile, Costa Rica), uma instituição não foi identificada. As instituições que possuem um maior número de pesquisadoras/es são a Fundação Oswaldo Cruz e a Universidade Federal de Santa Catarina. O total de pesquisadoras/es é 53 sendo que destas/es a maioria são mulheres $(82,4 \%)$ que pesquisam gênero na Educação Científica.

Foram encontrados artigos para todas as Unidades de Registro (UR) elaboradas, e foi necessária a elaboração de duas UR emergentes. No quadro 02 é apresentada uma breve descrição dos artigos encontrados na pesquisa e suas classificações nas UR.

\begin{tabular}{|c|c|c|c|}
\hline Nr. & $\begin{array}{c}\text { Autores/a } \\
\text { no }\end{array}$ & Descrição das pesquisas & $\mathbf{U R}$ \\
\hline 1 & $\begin{array}{l}\text { Scalfi e } \\
\text { Oliveira } \\
(2015)\end{array}$ & $\begin{array}{l}\text { É uma análise do filme Frankenweenie que transmite imagens que } \\
\text { contribuem para reforçar estereótipos conservadores e convencionais da } \\
\text { mulher. }\end{array}$ & 7 \\
\hline 2 & $\begin{array}{l}\text { Da Silva, } \\
\text { Barbosa, } \\
\text { Souza } \\
(2015)\end{array}$ & $\begin{array}{l}\text { Neste artigo são relacionadas abordagens da neurociência cognitiva e } \\
\text { habilidades de gênero no Programa de Avaliação de Estudante Internacional } \\
\text { (Pisa). Os resultados indicam que diferenças de gênero, em relação às } \\
\text { habilidades cognitivas podem estar relacionadas às dimensões educacionais } \\
\text { e socioculturais nas quais meninos e meninas são expostos. }\end{array}$ & 8 \\
\hline 3 & $\begin{array}{l}\text { Menezeset } \\
\text { al., (2017) }\end{array}$ & $\begin{array}{l}\text { Neste artigo, são analisados os números de ingressantes e concluintes dos } \\
\text { cursos de licenciatura, bacharelado, mestrado e doutorado em física da } \\
\text { UFSC. Os dados apontam para uma grande predominância masculina e a } \\
\text { proporção de mulheres é menor conforme o avanço da carreira. }\end{array}$ & 5 \\
\hline 4 & $\begin{array}{l}\text { Rodrigues, } \\
\text { Guimarães } \\
\text { (2016) }\end{array}$ & $\begin{array}{l}\text { Este estudo teve por objetivo delinear a participação feminina na pesquisa } \\
\text { na Fundação Oswaldo Cruz (Fiocruz). Os resultados apontam que a } \\
\text { produção bibliográfica das mulheres em números absolutos é maior que a } \\
\text { dos homens, mas eles apresentam produção média superior. }\end{array}$ & 5 \\
\hline 4 & $\begin{array}{l}\text { Galindo } \\
\text { (2016) }\end{array}$ & $\begin{array}{l}\text { Neste artigo é discutida a política de gênero no combate às desigualdades } \\
\text { de gênero propostas pela União Europeia (UE) para estabelecer mecanismos } \\
\text { de igualdade de gênero em Ciência e tecnologia. }\end{array}$ & 5 \\
\hline 4 & $\begin{array}{l}\text { Sombrio } \\
(2016)\end{array}$ & $\begin{array}{l}\text { Este artigo propõe analisar a presença de mulheres em expedições } \\
\text { científicas no Brasil em meados do século XX. }\end{array}$ & 5 \\
\hline 4 & $\begin{array}{l}\text { Cordero } \\
(2017)\end{array}$ & $\begin{array}{l}\text { Este artigo discute os esforços da Universidade da Costa Rica para } \\
\text { incorporar a perspectiva de gênero e os estudos feministas. O artigo reflete } \\
\text { os avanços alcançados na universidade e relata outros estudos da presença } \\
\text { de homens e mulheres nos campos da Ciência e da tecnologia. Conclui que, } \\
\text { apesar da presença feminina ainda há desigualdades na participação e no } \\
\text { acesso as carreiras. Alguns campos das Ciências básicas e da tecnologia, } \\
\text { como os campos da engenharia, têm uma menor presença de mulheres. }\end{array}$ & 5 \\
\hline 4 & $\begin{array}{l}\text { Graf, Rius } \\
(2017)\end{array}$ & $\begin{array}{l}\text { Neste texto, se propõem a revisão de uma política de Ciência e tecnologia } \\
\text { com uma perspectiva de gênero que garanta o caminho da transformação e } \\
\text { a inclusão de mulheres na Ciência. }\end{array}$ & 5 \\
\hline 5 & $\begin{array}{l}\text { González } \\
(2013)\end{array}$ & $\begin{array}{l}\text { O propósito da investigação foi o de caracterizar concepções de gênero e } \\
\text { Ciência de uma professora e um professor durante uma intervenção } \\
\text { pedagógica. A autora sugere que distintas fundamentações teóricas auxiliam } \\
\text { na superação da visão androcêntrica da Ciência. }\end{array}$ & 4 \\
\hline
\end{tabular}




\begin{tabular}{|c|c|c|c|}
\hline 5 & $\begin{array}{l}\text { Silva e } \\
\text { Ribeiro } \\
(2014)\end{array}$ & $\begin{array}{l}\text { Na pesquisa é abordado a trajetória acadêmica e profissional de mulheres na } \\
\text { Ciência por meio de entrevistas realizadas com cientistas em universidades } \\
\text { públicas. O artigo revela situações explícitas e implícitas de preconceitos de } \\
\text { gênero e evidencia a problemática de conciliar sua profissão com as } \\
\text { responsabilidades familiares. }\end{array}$ & 5 \\
\hline 6 & $\begin{array}{l}\text { Gioppo } \\
(2012)\end{array}$ & $\begin{array}{l}\text { A autora apresenta as reflexões do critério "preconceito", em especial o de } \\
\text { gênero, na avaliação de livros didáticos de Ciências. O critério preconceito } \\
\text { (especialmente o de gênero) utilizado pelo Programa Nacional do Livro } \\
\text { Didático (PNLD) é um critério de amplo escopo, difuso, cheio de sutilezas. }\end{array}$ & 1 \\
\hline 6 & $\begin{array}{l}\text { Pereira, } \\
\text { Monteiro } \\
(2015)\end{array}$ & $\begin{array}{l}\text { Este estudo analisa como os temas sexualidade e gênero são abordados na } \\
\text { produção acadêmica da área de Ensino/Educação. Os achados revelam } \\
\text { lacunas, avanços e desafios na incorporação da dimensão sociocultural da } \\
\text { sexualidade e do gênero na pesquisa e na prática do ensino nos diferentes } \\
\text { níveis de escolaridade. }\end{array}$ & 10 \\
\hline 6 & $\begin{array}{l}\text { Bastos, } \\
\text { Lüdke } \\
(2017)\end{array}$ & $\begin{array}{l}\text { Foi realizada uma intervenção com alunas do ensino médio com o objetivo } \\
\text { de tornar explícito o que pensam da gravidez na adolescência. Os resultados } \\
\text { apontam para um pensamento homogêneo entre esses sujeitos e remetem a } \\
\text { uma forma negativa de lidar com a sexualidade, expondo uma profunda } \\
\text { desigualdade no tratamento entre gêneros. }\end{array}$ & 6 \\
\hline 7 & $\begin{array}{l}\text { Bozal } \\
(2008)\end{array}$ & $\begin{array}{l}\text { O artigo discute o teto de vidro da Ciência em relação à participação das } \\
\text { mulheres no desenvolvimento do conhecimento científico }\end{array}$ & 5 \\
\hline 8 & $\begin{array}{l}\text { Freitas, } \\
\text { Teixeira } \\
\text { (2017) }\end{array}$ & $\begin{array}{l}\text { O texto trata da quase ausência de mulheres nas principais academias } \\
\text { científicas do Brasil e entre os vencedores do Prêmio Nobel e como tal fato } \\
\text { ajuda a desestimular que alunas ingressem nas carreiras científicas, já que, } \\
\text { inconscientemente, essas instituições passam a ideia de que a Ciência é } \\
\text { masculina. }\end{array}$ & 5 \\
\hline 9 & $\begin{array}{l}\text { Pinho } \\
(2017)\end{array}$ & $\begin{array}{l}\text { Este artigo reflete o campo da Biologia, no sentido de perceber o viés } \\
\text { androcêntrico que atravessa essa Ciência, partindo de um olhar da práxis } \\
\text { educativa de docentes do ensino médio. Começa destacando a importância } \\
\text { da Biologia para a Ciência e sua relação com a categoria gênero e segue } \\
\text { revelando as mensagens subliminares estereotipadas das práticas docentes. }\end{array}$ & 4 \\
\hline 10 & $\begin{array}{l}\text { Chaves } \\
(2014)\end{array}$ & $\begin{array}{l}\text { O objetivo deste artigo é analisar como as relações de gênero manifestadas } \\
\text { nos fundamentos teóricos da disciplina de Ciências Naturais do ensino } \\
\text { fundamental I caracterizam os indivíduos em identidades binárias e } \\
\text { dicotômicas sublimando, por conseguinte, a hierarquia de gênero presente } \\
\text { nos conteúdos didáticos desses materiais. }\end{array}$ & $\mathbf{1}$ \\
\hline 11 & $\begin{array}{l}\text { Santos, } \\
\text { German, } \\
\text { Cervi } \\
(2012)\end{array}$ & $\begin{array}{l}\text { Este artigo faz uma análise de imagens presentes em três livros didáticos de } \\
\text { ciências à luz do conceito de dominação masculina desenvolvido por Pierre } \\
\text { Bourdieu. São analisadas duas categorias de imagens o atlas do corpo } \\
\text { humano e de atividades físicas que tem como elemento principal o corpo } \\
\text { masculino e feminino. As considerações finais apontam para uma } \\
\text { problematização do livro didático enquanto instrumento de formação de } \\
\text { conceitos e subjetividades escolarizadas }\end{array}$ & 1 \\
\hline 12 & $\begin{array}{l}\text { Lima, } \\
\text { Rezende, } \\
\text { Ostermann } \\
(2011)\end{array}$ & $\begin{array}{l}\text { O estudo investiga discursos de estudantes em relação a suas preferências } \\
\text { por disciplinas e profissões. Os discursos adotados por meninas e meninos } \\
\text { podem estar relacionados as disparidades de gênero na Educação Científica. }\end{array}$ & 2 \\
\hline 12 & $\begin{array}{l}\text { Freitas e } \\
\text { Chaves } \\
(2013)\end{array}$ & $\begin{array}{l}\text { O artigo apresenta o discurso biológico/científico em quatro reportagens da } \\
\text { revista Superinteressante. Os autores evidenciam justificativas } \\
\text { naturalizadas de masculinidades e feminilidades como evidências } \\
\text { biológicas. }\end{array}$ & 7 \\
\hline 13 & $\begin{array}{l}\text { Neto Pinto, } \\
\text { Silveira } \\
\text { (2009) }\end{array}$ & $\begin{array}{l}\text { Este texto analisa artigos de história da ciência presentes nos periódicos } \\
\text { Química Nova e Química Nova na Escola, da Sociedade Brasileira de } \\
\text { Química (1978 a 2004), com o foco na participação das mulheres. Dos cento } \\
\text { e quatorze textos de história da Ciência, apenas seis discutem a presença (ou } \\
\text { ausência) das mulheres na Ciência. Esses textos consideram que, ao longo } \\
\text { do desenvolvimento científico, a participação feminina foi pouco } \\
\text { reconhecida e ainda dificultada pelos membros da Ciência. }\end{array}$ & 5 \\
\hline
\end{tabular}




\begin{tabular}{|c|c|c|c|}
\hline 13 & $\begin{array}{l}\text { Teixeira, } \\
\text { Freitas } \\
(2014)\end{array}$ & $\begin{array}{l}\text { Neste artigo são discutidas questões relativas aos processos de inserção e } \\
\text { aos comportamentos profissionais de acadêmicas na docência do ensino } \\
\text { superior em Física de dois centros federais de ensino e pesquisa da região } \\
\text { Sudeste. Os dados mostram que o comportamento das acadêmicas varia da } \\
\text { competição (com colegas de mesmo nível) ao apoio e incentivo (em relação } \\
\text { às alunas, sobretudo às discriminadas por cientistas homens). }\end{array}$ & 4 \\
\hline 13 & $\begin{array}{l}\text { Magalhães, } \\
\text { Caseira } \\
(2016)\end{array}$ & $\begin{array}{l}\text { O presente artigo analisou as enunciações e significados construídos pelas } \\
\text { mulheres cientistas ganhadoras do Programa "Para Mulheres na Ciência" no } \\
\text { Brasil. Foram analisados os discursos da escolha de seguir a carreira de } \\
\text { cientista e o que representa essa premiação. A análise dos dados possibilitou } \\
\text { a reflexão acerca das escolhas e caminhos transitados até chegar à carreira } \\
\text { de cientista. }\end{array}$ & 5 \\
\hline 14 & $\begin{array}{l}\text { Heerdt, } \\
\text { Batista } \\
(2016 b)\end{array}$ & $\begin{array}{l}\text { Na investigação é apresentado o encaminhamento teórico e metodológico } \\
\text { de uma Unidade Didática que tem como objetivo desconstruir visões } \\
\text { equivocadas de aspecto da Natureza da Ciência e desnaturalizar o papel } \\
\text { secundário da mulher na construção do conhecimento científico e na Ciência } \\
\text { como um processo de formação docente. }\end{array}$ & 4 \\
\hline 15 & $\begin{array}{l}\text { Heerdt, } \\
\text { Batista } \\
(2016 \mathrm{a})\end{array}$ & $\begin{array}{l}\text { Foram analisados discursos de docentes que participam de um processo de } \\
\text { formação com foco em Educação Científica e as questões de gênero, essa } \\
\text { investigação mostrou que há resistência, recorrente discurso de } \\
\text { naturalização e de negação da existência das questões de gênero na Ciência } \\
\text { e no Ensino de Ciências e que as falas de dominação masculina são mais } \\
\text { articuladas. }\end{array}$ & 4 \\
\hline 15 & $\begin{array}{l}\text { Silva, } \\
\text { Coutinho } \\
(2016)\end{array}$ & $\begin{array}{l}\text { O artigo faz uma análise dos livros didáticos de Biologia em relação aos } \\
\text { hormônios "sexuais". Na análise dos livros é encontrado um discurso } \\
\text { essencialista, segundo a qual existe uma natureza biológica que determina } \\
\text { os papéis sexuais de machos e fêmeas humanos. }\end{array}$ & \\
\hline 16 & $\begin{array}{l}\text { Heerdt, } \\
\text { Batista } \\
(2017)\end{array}$ & $\begin{array}{l}\text { O artigo analisa as representações sociais (RS) de docentes a respeito da } \\
\text { Natureza da Ciência (NdC), das questões de gênero na sociedade, na Ciência } \\
\text { e no contexto de ensino. Nas áreas de formação das/dos docentes, não foi } \\
\text { possível encontrar diferenças significativas nas RS, percebe-se, no entanto, } \\
\text { argumentação distinta de homens e de mulheres. A RS dos homens, } \\
\text { naturalizada, discriminatória e de negação das questões de gênero na } \\
\text { sociedade e na Ciência, mostra-se mais contundente do que das mulheres. }\end{array}$ & 4 \\
\hline 17 & $\begin{array}{l}\text { Soares, } \\
\text { Almeida } \\
(2016)\end{array}$ & $\begin{array}{l}\text { O objetivo deste artigo é analisar e compreender como o Grupo de Trabalho } \\
4 \text { - Didática e o Grupo de Trabalho } 23 \text { - Gênero, Sexualidade e Educação } \\
\text { da Associação Nacional de Pós-Graduação e Pesquisa em Educação } \\
\text { (ANPEd) vêm concebendo pesquisas de gênero e sexualidade com foco no } \\
\text { ensino de Ciências. Há uma reduzida abordagem científica das temáticas de } \\
\text { gênero e sexualidade no contexto das práticas pedagógicas no universo do } \\
\text { ensino de Ciências. }\end{array}$ & 10 \\
\hline 18 & $\begin{array}{l}\text { Agrello, } \\
\text { Garg } \\
(2009)\end{array}$ & $\begin{array}{l}\text { O artigo fará uma revisão do atual status da mulher na física, focalizando } \\
\text { em especial países em desenvolvimento, como Brasil e Índia. }\end{array}$ & 5 \\
\hline 18 & $\begin{array}{l}\text { Foote, } \\
\text { Garg } \\
(2015)\end{array}$ & $\begin{array}{l}\text { Foi realizada uma pesquisa nas áreas de ciências exatas, com brasileiras, } \\
\text { indianas e americanas, para identificar os fatores que influenciaram sua } \\
\text { escolha de área, bem como seus planos para carreira. As diferenças e as } \\
\text { influencias comuns entre as culturas tem implicações práticas em técnicas } \\
\text { para ajudar a atrair e manter as mulheres nas Ciências. }\end{array}$ & 2 \\
\hline 19 & $\begin{array}{l}\text { Lima } \\
\text { Junior, } \\
\text { Ostermann } \\
\text {, Rezende } \\
(2010)\end{array}$ & $\begin{array}{l}\text { A pesquisa buscou investigar a construção de lideranças na dinâmica } \\
\text { discursiva de um debate sobre Mecânica Quântica entre estudantes de um } \\
\text { curso de graduação em Física e possíveis relações com as diferenças de } \\
\text { gênero. Foi possível perceber que a liderança durante a atividade foi } \\
\text { majoritariamente exercida por meninos. As estratégias utilizadas pelas } \\
\text { meninas para lidar com a dominação masculina foram analisadas e } \\
\text { discutidas. }\end{array}$ & 9 \\
\hline 20 & $\begin{array}{l}\text { Santos } \\
(2014)\end{array}$ & $\begin{array}{l}\text { A pesquisa problematizou categorias de representação de gênero em um } \\
\text { livro didático de matemática, utilizado por estudantes do Ensino Médio de } \\
\text { uma instituição de ensino em Minas Gerais, e constatou como tais } \\
\text { representações ainda legitimam posições hierarquizantes de sujeito, }\end{array}$ & 1 \\
\hline
\end{tabular}




\begin{tabular}{|l|l|l|l|}
\hline & & $\begin{array}{l}\text { (re)produzem os estereótipos de gênero e diversidade presentes na educação } \\
\text { e em nossa sociedade. }\end{array}$ & \\
\hline 21 & $\begin{array}{l}\text { Porro } \\
(2012)\end{array}$ & $\begin{array}{l}\text { Embora nos últimos anos os conteúdos do CTS tenham sido incluídos no } \\
\text { currículo científico, a questão de gênero ainda pertence de alguma forma ao } \\
\text { currículo oculto. Nesse sentido, grande parte das/dos docentes continua } \\
\text { transmitindo uma visão androcêntrica da Ciência. A superioridade "natural" } \\
\text { dos homens sobre as mulheres, que parece inofensiva em termos científicos, } \\
\text { contribui para perpetuar graves problemas sociais, como a violência de } \\
\text { gênero e a desigualdade no acesso à educação e ao trabalho. }\end{array}$ & $\mathbf{4}$ \\
\hline 22 & $\begin{array}{l}\text { Cruz } \\
(2014)\end{array}$ & $\begin{array}{l}\text { O objetivo deste artigo é discutir as contribuições da epistemologia } \\
\text { feminista à Ciência e à pesquisa nas ciências humanas e sociais. A reflexão } \\
\text { parte da crítica da produção do conhecimento científico e enfatiza a } \\
\text { importância dos estudos de gênero na produção do conhecimento. }\end{array}$ & $\mathbf{3}$ \\
\hline
\end{tabular}

Quadro 2: Resumo dos artigos e suas classificações nas Unidades de Registro.

Fonte: Autoras (2018).

Gênero e materiais didáticos. Nessa UR foram encontrados cinco artigos. O livro didático legitima o discurso científico na escola e, muitas vezes, é o único material utilizado, por opção ou não, pelas/os docentes no processo de ensino. Nos artigos classificados nesta UR são analisados os conteúdos e imagens em livros de Ciências e Matemática, todos demonstram que existem preconceitos de gênero, reprodução de estereótipos, hierarquia de gênero em que o masculino é privilegiado em relação ao feminino. Esses materiais reforçam a ideia de que a Ciência não é um lugar para as mulheres. As pesquisas discutem necessidade de um/a docente crítico/a em relação às questões de gênero e o uso de materiais didáticos diversificados (CHAVES, 2014; SANTOS; GERMANO; CERVI, 2012; SANTOS, 2014).

No artigo de Silva e Coutinho (2016) é analisada a apresentação dos hormônios ditos "sexuais", que se apresentam essencialistas e reproduzem uma forma de ignorância em Biologia que possibilita o sexismo e a discriminação de gênero.

No artigo de Gioppo (2012) é apresentada outra problemática relacionada a fragilidade do modelo de avaliação do PNLD, que apesar de apresentar o critério preconceito em relação a gênero, esse é muito amplo e difuso. A avaliação dos livros didáticos, tanto pelo PNLD quanto pelos/as docentes deveria levar em consideração a história da presença e ausência de homens e mulheres na Ciência, como o feminino e masculino é representado, além de uma análise crítica de como a Ciência investiga os conteúdos da Ciência que estão carregados de estereótipos e preconceitos de gênero.

Gênero e inferências de interpretação. Nesta UR foram classificados dois artigos que estudam o interesse de meninas e meninos pela Ciência. A questão do desinteresse das mulheres por carreiras científicas é uma discussão internacional, por exemplo, o projeto TWIST (Towards Women in Science \& Tecnology) discute o fato de 
que as mulheres, hoje, detêm apenas $12 \%$ dos altos cargos na área científica na Europa e que a diversidade de gênero é essencial para a criatividade e inovação na Ciência (HEERDT, 2014). O artigo de Lima, Rezende e Ostermann (2011) faz uma análise dos discursos de estudantes em relação a suas preferências por disciplinas e profissões, as meninas possuem uma inclinação por carreiras como Medicina, Ciências Humanas e Ciências Sociais Aplicadas, os meninos são mais preocupados com os salários e estabilidade no emprego, esses discursos adotados podem estar relacionados às disparidades de gênero na Educação Científica.

No artigo de Foote e Garg (2015) buscaram compreender os fatores que influenciaram brasileiras, indianas e americanas, a escolherem a área de ciências exatas. Percebem que existem diferenças e influências culturais, essas cientistas, principalmente as indianas e brasileiras, descrevem que gênero impacta negativamente e que algumas barreiras precisam ser superadas para que consigam sentir-se a vontade como cientistas.

Muitos estudantes possuem uma visão equivocada do trabalho e do individuo cientista, essas barreiras precisam ser extrapoladas para aumentar a representação de mulheres estudando e trabalhando nas diversas áreas científicas. Na Educação Científica deve-se garantir que as meninas sejam expostas a uma ampla variedade de opções de carreiras científicas, isso pode incentivar estudantes a pensar num futuro como profissionais da Ciência. Além disso, vincular estudantes do ensino médio e graduação a mulheres cientistas que poderiam orientar e apresentar como se realiza o trabalho científico, pode ser uma forma de desmisticar o trabalho científico.

Gênero e estudos teóricos. Nessa UR foi classificado um artigo que trata da necessidade da incorporação das discussões de gênero na Educação Científica. Cruz (2014) discute as contribuições da epistemologia feminista à Ciência e à pesquisa nas ciências humanas e sociais. A reflexão parte da crítica da produção do conhecimento científico como neutro, universal, objetivo e androcêntrico. Enfatiza a importância dos estudos das relações de gênero na produção do conhecimento. E alerta para os sexismos e hierarquizações, baseadas no gênero que limitam o potencial humano, as "diferenças não constituem, a priori, desigualdades. "O reconhecimento das diferenças e o respeito à alteridade são parte importante ao legado feminista, é um importante passo a ser dado na direção de uma sociedade mais justa e igualitária” (p. 26). Esse é um texto de base teórica para os estudos de gênero na Educação Científica.

Gênero, práticas e formação docente. Nessa UR foram classificados sete artigos. O trabalho de Porro (2012) apresenta a problemática da percepção equivocada de 
docentes em relação à CTS, para mudança de tais concepções a autora propõem uma intervenção pedagógica que envolva a Ciência e Tecnologia na Sociedade e o subtema contribuição ao pensamento social abordando questões de gênero. No artigo de González (2013) o propósito da investigação foi o de identificar e caracterizar concepções de gênero e Ciência. Foi realizado um estudo de caso comum a professora e um professor. A professora ampliou seus conhecimentos em relação aos aspectos contextuais da atividade científica, no entanto, manteve algumas concepções androcêntricas. $O$ professor possui uma noção antagônica entre os papeis de mulher e cientista. A autora sugere que distintas fundamentações teóricas auxiliam na superação da visão androcêntrica da Ciência.

As pesquisadoras Heerdt e Batista (2016a) analisam os discursos das/os docentes que participam de um processo de formação com foco em Educação Científica e as questões de gênero, essa investigação mostrou que há resistência, recorrente discurso de naturalização e de negação na existência das questões de gênero na Ciência e no Ensino de Ciências e que as falas de dominação masculina são mais articuladas. Em outro artigo Heerdt e Batista (2017) analisam as representações sociais (RS) de docentes a respeito da Natureza da Ciência (NdC), das questões de gênero na sociedade, na Ciência e no contexto de ensino. Nas áreas de formação das/dos docentes, não foi possível encontrar diferenças significativas nas RS, percebe-se, no entanto, argumentação distinta de homens e de mulheres. A RS dos docentes é naturalizada, discriminatória e de negação das questões de gênero na sociedade e na Ciência, essa RS mostra-se mais contundente do que das docentes.

O trabalho de Pinho (2017) vem corroborar com os anteriores. Esta pesquisadora durante três meses observou a prática de cinco docentes do ensino médio em aulas de Biologia, na análise das falas do/das docentes, emergiram as categorias, marcadas e construídas pela exclusão e invisibilidade feminina e desigualdade em favor do masculino, com "concepções de homem como centro do universo, na linguagem e na contribuição à Ciência, da incapacidade cognitiva das mulheres para as áreas das Ciências Exatas e Matemáticas” (p. 42).

Ao que parece a escola é um ambiente que está reproduzindo ao invés de provocar transformações no atual modelo social androcêntrico. Neste sentido, todas as pesquisas apontam para a formação e reflexão que possibilite as/os docentes reduzir as desigualdades entre homens e mulheres. O artigo de Heerdt e Batista (2016b) apresenta um encaminhamento teórico e metodológico de uma Unidade Didática para a formação docente que tem como objetivo "desconstruir visões equivocadas de aspectos da Natureza 
da Ciência e desnaturalizar o papel secundário da mulher na construção do conhecimento científico e na Ciência” (p. 55).

Em outra perspectiva o trabalho de Teixeira e Freitas (2014) discutem a inserção e os comportamentos adotados pelas docentes de Física em dois centros federais. Os dados mostram que para as docentes se inserirem neste campo, por vezes, negam a feminilidade e adotam uma postura masculina. Além de vítimas, as docentes, são agentes de discriminação e preconceito, e em outros momentos apoiam-se mutuamente para combater o comportamento hostil dos homens. Nas atividades como docentes identificaram conflitos, resistências e valores que, possivelmente, influenciam as práticas profissionais e as interações com pares de ambos os sexos.

Os trabalhos classificados na UR 4 reforçam a necessidade da formação explicita inicial e continuada, pois mostram que as/os docentes são despreparados para tratar e enfrentar as diversas situações que envolvem as questões de gênero na profissão docente. Vale ressaltar que não foram encontrados trabalhos que discutam de maneira sistemática a inserção das discussões de gênero na formação.

Gênero e a participação de Mulheres na Ciência. Nessa UR foram classificados 12artigos. Num passado não tão distante a Ciência era dominada por homens, hoje apesar das mulheres estarem presentes são necessárias políticas de inclusão como mostram os artigos de Graf e Rius (2017) e Galindo (2016). Graf e Rius (2017) discutem uma política de Ciência e Tecnologia numa perspectiva de gênero no México. O foco principal é a inclusão de mulheres nos sistemas de pesquisa e a perspectiva de gênero na construção do conhecimento científico, não é somente uma questão de incluir as mulheres na ciência, mas gradualmente reestruturar instituições de ensino superior e de pesquisa científica que garantam equidade e igualdade para o pleno desenvolvimento das mulheres. Essas autoras elencam uma série de recomendações de políticas públicas para eliminar as desigualdades persistentes e caminhar para uma equidade social. O artigo de Galindo (2016) discute a política de gênero no combate às desigualdades de gênero propostas pela União Europeia (UE) para estabelecer mecanismos de igualdade de gênero em Ciência e tecnologia. Este artigo apresenta uma introdução às políticas de igualdade de gênero no contexto europeu e comenta o seu impacto. Faz uma análise específica do caso da Alemanha, que apesar dos grandes esforços para institucionalizar as políticas de igualdade de gênero, as mulheres ainda estão sub-representadas na Ciência e na pesquisa.

O objetivo de tais políticas é aumentar a participação das mulheres no sistema científico e fomentar a pesquisa no campo de gênero e feminismos. Nos dois artigos o 
ensino de Ciências está diretamente relacionado às políticas de igualdade e respeito à diferença.

Outras publicações classificadas na UR5 tratam de analisar as desigualdades nas carreiras científicas, na ascensão e representação das mulheres, com análises das dificuldades e obstáculos enfrentados pelas cientistas. A pesquisa de Rodrigues e Guimarães (2016) delineou a participação feminina na Fundação Oswaldo Cruz (Fiocruz) e os resultados apontam que a produção bibliográfica das mulheres em números absolutos é maior que a dos homens, mas eles apresentam produção média superior. Nos postos de tomada de decisão na Fiocruz os dados sugerem, no geral, segregação hierárquica (ou vertical), fenômeno conhecido na literatura como "teto de vidro", que se caracteriza pela menor velocidade das mulheres na ascensão da carreira, em comparação com a progressão profissional masculina, o que resulta na sub-representação das mulheres nos postos de tomada de decisão e, consequentemente, limita o alcance de posições de maior prestígio na instituição.

O artigo de Bozal (2008) também discute o teto de vidro da Ciência em relação à participação das mulheres no desenvolvimento do conhecimento científico. Em outros países, a questão do teto de vidro não é distinta, na Universidade da Costa Rica são realizados esforços para incorporar a perspectiva de gênero e os estudos feministas, no entanto, apesar da presença feminina na universidade ainda há desigualdades na participação e no acesso as carreiras (CORDERO, 2017).

Na pesquisa de Menezeset al. (2017) são analisados os números de ingressantes e concluintes dos cursos de licenciatura, bacharelado, mestrado e doutorado em física da UFSC (1988 a 2017). Os dados apontam para uma grande predominância masculina, maior que $76 \%$, e a proporção de mulheres é menor conforme o avanço da carreira. A pesquisa anterior corrobora com a de Agrello e Garg (2009) que fazem uma revisão do atual status da mulher na física, focalizando em especial países em desenvolvimento, como Brasil e Índia e mostram a sub-representação das mulheres neste campo. A falta de representação e a ausência de mulheres nas principais academias científicas do Brasil e entre os vencedores do Prêmio Nobel é um fato que ajuda a desestimular alunas a ingressarem nas carreiras científicas, já que, inconscientemente, essas instituiçõos passam a ideia de que a Ciência é masculina, essa é a discussão do artigo de Freitas (2017).

Numa perspectiva histórica da participação das mulheres na Ciência foram encontrados dois artigos. O de Sombrio (2016) que propõe analisar a presença de mulheres em expedições científicas no Brasil em meados do século XX e as diversas 
formas como implicações de gênero influenciavam essas trajetórias. E o de Neto Pinto e Silveira (2009) que analisa artigos de história da Ciência, com o foco na participação das mulheres. Dentre 114 textos de história da Ciência, apenas seis discutem a presença ou ausência das mulheres. Esses textos consideram que, ao longo do desenvolvimento científico, a participação feminina foi pouco reconhecida e ainda dificultada pelos membros da Ciência. Esses estudos que evidenciam a mulher e a sua contribuição para a Ciência, podem no Ensino de Ciências visibilizarem as mulheres no processo de construção do conhecimento científico.

Atualmente as pesquisadoras ainda sofrem situações explícitas e implícitas de preconceitos de gênero e de dificuldades em conciliar sua profissão com as responsabilidades familiares, é o que descreve a pesquisa de Silva e Ribeiro (2014) que abordaram a trajetória acadêmica e profissional de mulheres na Ciência por meio de entrevistas realizadas com cientistas em universidades públicas. No artigo de Magalhães e Caseira (2016) analisam as enunciações e significados construídos pelas mulheres cientistas ganhadoras do Programa "Para Mulheres na Ciência" no Brasil. Foram analisados os discursos da escolha de seguir a carreira de cientista e o que representa essa premiação. A análise mostra que a escolha da profissão é considerada pelas cientistas essencialista, e não como escolha e esforço pessoal. Quanto à representação da premiação estão vinculadas a reconhecimento e visibilidade das cientistas.

Gênero e Intervenções. Nesta UR foi classificado um artigo, o de Bastos e Lüdke (2017) em que foi realizada uma intervenção a partir do documentário "Meninas" com alunas do ensino médio com o objetivo de tornar explícito o que pensam da gravidez na adolescência. Os resultados apontam para uma profunda desigualdade no tratamento entre gêneros, imprimindo julgamentos depreciativos em relação à mulher e à mulher-mãe.

Gênero e Ciência na Mídia. Nesta UR foram classificados dois artigos, o de Scalfi e Oliveira (2015) fazem uma análise do filme Frankenweenie. Este filme transmite imagens que contribuem para reforçar estereótipos conservadores e convencionais da mulher. Os estereótipos de cientista são mantidos como ser homem, egocêntrico, que trabalham em laboratórios de cenário mágico onde coisas impossíveis podem acontecer. O artigo de Freitas e Chaves (2013) investigam o discurso biológico/científico em quatro reportagens da revista Superinteressante. Os autores evidenciam justificativas naturalizadas de masculinidades e feminilidades como evidências biológicas, fundamentando "formas supostamente naturais de ser homem ou ser mulher e comportamentos esperados socialmente". 
É interessante perceber que a mídia transmite, muitas vezes, a imagem de mulheres e homens de forma naturalizada e sem reflexões. Nesse sentido, reafirma-se que as/os docentes precisam estar sensíveis às questões de gênero para poderem perceber tais problemáticas nos mais diversos materiais a serem utilizados em sala de aula.

Gênero e aprendizagem de Ciências. Nesta UR foi classificado um artigo. Culturalmente fomos bombardeados pela ideia de que as mulheres são inferiores aos homens, essa é uma problemática controversa, que tem sido severamente combatida. No artigo de Da Silva, Barbosa e Souza (2015) é realizada uma análise do Programa de Avaliação de Estudante Internacional (Pisa) de um modo geral, o exame mostra a fragilidade do ensino brasileiro. Na resolução de problemas as meninas têm um menor desempenho, o que corrobora com a pesquisa de Eliot (2013 apud DA SILVA; BARBOSA; SOUZA, 2015, p. 21), “a partir da adolescência se evidencia nas meninas um desempenho inferior em ciência, matemática e áreas relacionadas". As/o autoras/s enfatizam a influência cultural a qual meninos e meninas são expostas, como: brinquedos, atividades esportivas, estereótipos culturais, preconceitos, expectativa da família e escola, além de conteúdos, informações e materiais didáticos podem contribuir para consolidar as diferenças de gênero.

Interações/percepções em aulas de Ciências. Esta UR foi elaborada para pesquisas que buscam compreender as interações entre os indivíduos em aulas de Ciências e foi emergente para esta pesquisa, sendo classificado um artigo, o de Lima Junior, Ostermann e Rezende (2010) que confirmam as assimetrias de gênero, em aulas de mecânica quântica. Os meninos assumem a liderança majoritariamente durante a atividade. Em nenhum momento as meninas disputaram a liderança. A pesquisa demonstra a desigualdade nos debates acadêmicos e alerta para a reprodução das desigualdades de gênero que nem sempre são consideradas no processo de ensino.

Gênero e produção científica. Esta UR foi emergente para esta pesquisa e foram classificados dois artigos. No estudo de Pereira e Monteiro (2015) analisaram como os temas sexualidade e gênero são abordados na produção acadêmica da área de Ensino/Educação (2006 a 2011). Em específico em relação a gênero foram encontrados 15 artigos na área de Educação em geral, não específico em Ensino de Ciências, os artigos analisam os papéis sociais de gênero, apontam e questionam representações binárias e normativas, indicam que a prática pedagógica poderia contribuir para a igualdade de gênero ao questionar a negação ou manutenção das dinâmicas estabelecidas entre os gêneros. Encontram artigos que focalizam na diferença de desempenho escolar ou o grau 
de escolarização entre os sexos, desigualdades no cotidiano e relações de poder. Em outros, as investigações discutem como o conceito é problematizado em artigos ou documentos de referência.

A investigação de Soares e Almeida (2016) busca compreender como dois grupos de trabalho, Didática e Gênero, Sexualidade e Educação, da ANPEd vêm concebendo pesquisas de gênero e sexualidade com foco no ensino de Ciências. Existem poucas pesquisas publicadas, seis nos dois grupos de trabalho em relação ao Ensino de Ciências, e todos com um enfoque de discussão em sexualidade e diversidade sexual e nenhum nas relações de gênero.

\section{Considerações finais}

Esta pesquisa teve como objetivo compreender o desenvolvimento das pesquisas em gênero e Ensino de Ciências no Brasil a partir dos periódicos A1, A2 e B1 nacionais da área de Ensino e avaliar as lacunas e discutir os possíveis encaminhamentos para as pesquisas na área, para que se possa como pesquisadoras/es formular prioridades de pesquisa a médio e longo prazo.

As pesquisas em maior quantidade são em relação participação de Mulheres na Ciência que analisam a presença histórica e os obstáculos enfrentados por essas cientistas, essas investigações permitem que o Ensino de Ciências ultrapasse visões equivocadas de quem faz Ciência, apesar das dificuldades as mulheres estão produzindo conhecimento e que "Ciência também é coisa de menina".

Em relação as pesquisas de materiais didáticos e formação docente houve um crescimento ao comparar com pesquisas anteriores. No entanto, ainda são necessárias pesquisas que analisem esses materiais a partir da epistemologia feminista com questões de quem, como, o que a Ciência produz, além do conteúdo da Ciência com um olhar de gênero. Essas questões também precisam ser refletidas explicitamente na formação docente, pois as questões que gênero são naturalizadas e pouco, ou quase nunca, percebidas.

Muitas são as lacunas, são necessários estudos aprofundados de como meninas e meninos percebem e se interessam pela Ciência, hoje as pesquisas indicam a antipatia a essa área e são perdidos nas escolas futuros/as cientistas. As investigações das interações nas aulas de ciências precisam ser mais bem compreendidas, as que se dedicam a essas 
investigações mostram, como ocorrem hoje, as interações em sala de aula, e essas interações afastam meninas e mulheres das discussões científicas.

No que diz respeito as pesquisas de intervenções pedagógicas no ensino básico e/ou superior são raras, uma em 90 revistas, em dez anos de pesquisa. As intervenções poderiam promover a discussão explicita das questões de gênero na Ciência, com diversos enfoques, como por exemplo, a participação das mulheres na Ciência, o viés de gênero na pesquisa científica, desde escolhas teóricas e metodológicas e dos próprios resultados da Ciência. É necessário e urgente avançar nessa linha de pesquisa com base teórica nos estudos feministas da Ciência.

Os 34 artigos classificados nas dez unidades de registro elaboradas ainda não representam a área como um todo, mas podem dar indicativos das pesquisas. Percebe-se que com esse esforço metodológico de busca em um maior número de revistas, quando comparado as pesquisas Batista et al., (2011) e Silva, Santos e Heerdt (2017), aumentou a diversidade dos temas abordados, com duas unidades de registro emergentes. Para pesquisas futuras é necessário ampliar os esforços de mapeamento em revistas internacionais, publicações em eventos científicos, teses e dissertações para compreender como as questões de gênero na Educação Científica estão sendo investigadas e surjam outras caracterizações.

Reitera-se a necessidade de ampliar e aprofundar as pesquisas em Gênero, Ciência e Educação Científica no que diz respeito a função social da Ciência e às intenções educacionais para que tenhamos a possibilidade de um ensino mais equânime para meninos e meninas.

\section{Referências}

ABD-EL-KHALICK, F.; BELL, R. L.; LEDERMAN, N.G. The nature of science and instructional practice: Making the unnatural natural. Science Education, s.1., v. 82, p. 417-436, 1998.

AGRELLO, D.A.; GARG, R. Mulheres na física: poder e preconceito nos países em desenvolvimento. Revista Brasileira de Ensino de Física, São Paulo, v. 31, n. 1, p. 1305.11305.6., 2009.

ANDERSON, E. Feminist Epistemology and Philosophy of Science. In: EDWARD N. (Ed.). ZALTA. The Stanford Encyclopedia of Philosophy (Spring 2011 edition), 2011.

BARDIN, L. Análise de conteúdo. 3. ed. Lisboa: Ed. 70, 2004. 
BASTOS, G. D.; LUDKE, E. Reflexões sobre gênero no ensino de biologia: um olhar sobre o discurso de estudantes do primeiro ano do ensino médio acerca da gravidez na adolescência. In: Revista Contexto e educação, s.1., v.32, n.101, p.142-174, 2017.

BATISTA, I. de L.; TOREJANI, A. T. C.; HEERDT, B.; LUCAS, L. B.; OHIRA, M. A.; CORREAA, M. L.; BARBOSA, R. G.; BASTOS, V. C. Gênero Feminino e Formação de Professores na Pesquisa em Educação Científica e Matemática no Brasil. In: ENCONTRO NACIONAL DE PESQUISA EM EDUCAÇÃO EM CIÊNCIAS, 2011. Anais ...[s.1.:s.n.], 2011.

BOZAL, A. G. Mujeres y ciencia: Techos de cristal. EccoS Revista Científica, São Paulo, v. 10, n. 1, p. 213-232, jan. /jun. 2008.

CHAVES, S. A. A Hierarquia De Gênero No Fundamento Teórico Da Disciplina De Ciências Naturais Do Ensino Fundamental I. Educação em Revista, Marília, v. 15, n. 01, p. 73- 90, janjun. 2014.

CORDERO, T. A Brief Review of Actions to Strengthen Gender Equality at the University of Costa Rica. Cadernos Pagu, Campinas, n.49, 2017.

CRUZ, M. A crítica feminista à ciência e contribuição à pesquisa nas ciências humanas. Revista Tempos e Espaços em Educação, São Cristóvão, v.7, n.12, p. 15-27. jan./abr. 2014.

DA SILVA, J.; BARBOSA, I.; DE SOUZA, J. Neurociência cognitiva e habilidades de gênero: uma analise do desempenho cognitivo de estudantes brasileiros avaliados no PISA. Revista Areté- Revista Amazônica de Ensino de Ciências, Manaus, v. 8, n. 15, p. 11-25, maio 2017. ISSN 1984-7505.

FAUSTO-STERLING, A. Sexing the Body: Gender Politics and the Construction of Sexuality. New York: Basic Books. 2000.

FOOTE, K.; GARG, R. A cross-cultural survey of female undergraduates' aspirations for scientific study and careers. Revista Brasileira de Ensino de Física, São Paulo, v. 37, n. 1, 2015.

FREITAS, L. M.; CHAVES, S. N. Desnaturalizando Os Gêneros: Uma Análise Dos Discursos Biológicos. Ensaio Pesquisa em Educação em Ciências, Belo Horizonte, v. 15, n. 3, p. 131148, 2013.

FREITAS, M. de A.; TEIXEIRA, A. B. M. A irrisória representação feminina no prêmio Nobel e nas academias científicas brasileiras. Educa - Revista Multidisciplinar em Educação, Porto Velho, v. 4, n. 9, p. 144-158, set./dez. 2017.

FRENCH, S. Ciência: conceitos-chave em filosofia.Porto Alegre: Artmed, 2009.

GALINDO, M. Z. Gender in science: The impact of equality policies in scientific institutions and practices: The case of Germany. Cadernos Pagu, Campinas, n. 47, 2016.

GIOPPO, C. Pollyana, tome a pílula vermelha! Mas, e depois? revisitando o preconceito de gênero nas avaliações dos livros didáticos de ciências.Revista Contexto e educação, s.1., v.27, n.88, p.103-125, jul/dez. 2012.

GONZÁLEZ, J. P. C. Concepciones Sobre Ciencia y Género En El Profesorado De Química: Aproximaciones Desde Un Estudio Colectivo De Casos. Ciência \& Educação, Baúru, v. 19, n. 2, p.323-338, 2013. 
GRAF, N. B.; RIUS, L. E. F. Política de Ciencia y Tecnología con Perspectiva de Género en México. Cadernos Pagu, Campinas, n.49, 2017.

HEERDT, B. Saberes docentes: Gênero, Natureza da Ciência e Educação Científica. n.f.. 2014. Tese (Doutorado em Ensino de Ciências e Educação Matemática) - Centro de Ciências Exatas, Universidade Estadual de Londrina, Londrina, 2014.

HEERDT, B.; BATISTA, I. de L. Questões de Gênero e da Natureza da Ciência na Formação Docente. Investigações em Ensino de Ciências, Porto Alegre, v. 21, n. 2, p. 30-51, 2016a.

HEERDT, B.; BATISTA, I. de L. Unidade Didática na Formação Docente: Natureza da Ciência e a visibilidade de Gênero na Ciência. Experiências em Ensino de Ciências, s. 1., v.11, n. 2, 39-60, $2016 b$.

HEERDT, B.; BATISTA, I. de L. Representações sociais de ciência e gênero no ensino de Ciências. Práxis Educativa, s. 1., v. 12, n. 3, p. 995-1012, 2017.

KELLER, Evelyn Fox. Qual foi o impacto do feminismo na ciência? Tradução de Maria Luiza Lara. Cadernos Pagu, Campinas, n.27, p. 13-34, 2006.

LIMA, P. J.; OSTERMANN, F.; REZENDE, F. Liderança e Gênero em um debate acadêmico entre graduandos em Física. Revista Brasileira de Pesquisa em Educação em Ciências, Belo Horizonte, v.10, n.1, 2010.

LIMA, P. J.; REZENDE, F.; OSTERMANN, F. Diferenças de Gênero nas Preferências Disciplinares e Profissionais de Estudantes de Nível Médio: Relações com a Educação em Ciências. Ensaio Pesquisa em Educação em Ciências, Belo Horizonte, v. 13, n.2, p.119-134, 2011.

LONGINO, H.; DOELL, R. Body, Bias, and Behavior: A Comparative Analysis of Reasoning in Two Areas of Biological Science. Signs, Winter, v. 9, n. 2, p. 206-227, 1983.

MAGALHÃES, J. C.; CASEIRA, F. F. Jovens cientistas: analisando a premiação "para mulheres na ciência”. Ensino em revista, s.1., v.23, n.2, p.387-410, 2016.

MENEZES, D. P.; BUSS, K.; SILVANO, C. A.; D’AVILA, B. N.; ANTENEODO, C. A física da UFSC em números: evasão e gênero. Caderno Brasileiro de Ensino de Física, s.l., v.35, n.1, p.324-336, abr. 2017.

NETO, P, da, C. P.; SILVEIRA, H. E. da. A História da Ciência: um olhar para periódicos brasileiros de química.Ensino em re-vista, s.l., v.16, n.1, p.105-122, 2009.

PEREIRA, Z. M.; MONTEIRO, S. S. Gênero e sexualidade no ensino de ciências no Brasil: análise da produção científica recente. RevistaContexto e Educação, s.1., v.30, n.95, p.117$146,2015$.

PINHO, M. J. S. A sala de aula de Biologia: espaço gendrado. Revista Educação, Cultura e Sociedade (ECS), Mato Grosso, v. 7, n. 1, p. 32- 44, jan/jun. 2017.

PORRO, S. Lascuestiones de género enelcurriculum (oculto) enlaenseñanza de las ciências.

Rencima - Revista de Ensino de Ciências e Matemática, s.l., v. 3, n.3, p. 25-36. 2012.

SILVA, F. A. R.; COUTINHO, F. A. Realidades colaterais e a produção da ignorância em livros didáticos de biologia: um estudo sobre os hormônios e a questão de gênero.Investigações em Ensino de Ciências, Porto Alegre, v. 21, n. 3, p. 176, 2016. 
RODRIGUES, J. G.; GUIMARAES, M. C. S. A Fundação Oswaldo Cruz e a ciência no feminino: a participação feminina na prática e na gestão da pesquisa em uma instituição de ensino e pesquisa. Cadernos Pagu, Campinas, n.46, p. 197-222. 2013.

SANTOS, C. K. Gênero em um Livro Didático do Ensino Médio: Problematizando Representações. Revista Eletrônica Debates em Educação Científica e Tecnológica, s.l., v. 04, n. 01, p. $52-51,2014$.

SANTOS, T. R.; GERMANO, A. P.; CERVI, G. M. As imagens do "natural": uma análise da dominação masculina nos livros didáticos de Ciências. Educação Teoria e Prática, Rio Claro, v. 22 , n. 41 , p. 82- 99.2012.

SCALFI, G. A. de M., OLIVEIRA, M. M. Cine y ciencia: unanálisis de losestereotipos presentes enla película infantil Frankenweenie, de Tim Burton. Alexandria Revista de Educação em Ciência e Tecnologia, s.l., v. 8, n. 2, p.183-197, 2015.

SCHIEBINGER, Londa. O feminismo mudou a ciência? Bauru, Edusc, 2001

SILVA, F. F.; RIBEIRO, P. R. C. Trajetórias de mulheres na ciência: "ser cientista" e "ser mulher". Ciência \& Educação, Bauru, v. 20, n. 2, p. 449-466, 2014.

SILVA, A. F.; SANTOS, A. P. O.; HEERDT, B. Questões de Gênero na Educação Científica: Tendências nas Pesquisas Nacionais e Internacionais. In: ENCONTRO NACIONAL DE PESQUISA EM EDUCAÇÃO EM CIÊNCIAS - ENPEC, 11. 2017. Florianópolis, SC, Anais... Florianópolis, SC: ABRAPEC, 2017.

SOARES, A. G.; ALMEIDA, D. M. Análise de trabalhos apresentados na anped (2004 a 2013) com a temática de gênero e sexualidade no ensino das ciências. Reflexão e Ação, Santa Cruz do Sul, v. 24, n. 1, p. 82-96, abr. 2016.

SOMBRIO, M. M. O. Em busca pelo campo - Mulheres em Expedições Científicas no Brasil em meados do século XX. Cadernos Pagu, Campinas, n.48, 2016.

TEIXEIRA, A. B. M.; FREITAS, M. de A. Mulheres na docência do ensino superior em cursos de física. Ensino em revista, s.1., v.21, n.2, p.329-340, 2014.

Recebido em: 17 de maio de 2018.

Aceito em: 26 de julho de 2018. 
Apêndice 01

\begin{tabular}{|c|c|c|c|c|c|c|c|c|c|c|c|c|}
\hline \multirow{2}{*}{ Nr. } & \multirow{2}{*}{ Revista } & \multicolumn{11}{|c|}{ Ano } \\
\hline & & 08 & 09 & 10 & 11 & 12 & 13 & 14 & 15 & 16 & 17 & 18 \\
\hline 0 & Abakós & & & & & & & & & & & \\
\hline 0 & Acta Scientiae & & & & & & & & & & & \\
\hline 1 & Alexandria & & & & & & & & 1 & & & \\
\hline 2 & Areté & & & & & & & & 1 & & & \\
\hline 0 & Atos de pesquisa em educação & & & & & & & & & & & \\
\hline 3 & Caderno Brasileiro de ensino de Física & & & & & & & & & & 1 & \\
\hline 0 & Cadernos CEDES & & & & & & & & & & & \\
\hline 0 & Cadernos CENPEC & & & & & & & & & & & \\
\hline 0 & Cadernos CIMEAC & & & & & & & & & & & \\
\hline 0 & Cadernos de Educação (UFPEL) & & & & & & & & & & & \\
\hline 0 & Cadernos de Pesquisa & & & & & & & & & & & \\
\hline 0 & Cadernos de pesquisa em educação & & & & & & & & & & & \\
\hline 0 & Cadernos de Pesquisa Fundação Carlos Chagas. & & & & & & & & & & & \\
\hline 0 & Cadernos de pesquisa: pensamento educacional & & & & & & & & & & & \\
\hline 4 & Cadernos pagu & & & & & & & & & 3 & 2 & \\
\hline 5 & Ciência e Educação & & & & & & 1 & 1 & & & & \\
\hline 0 & Ciência e Ensino & & & & & & & & & & & \\
\hline 6 & Contexto \& Educação & & & & & 1 & & & 1 & & 1 & \\
\hline 0 & Crítica educativa & & & & & & & & & & & \\
\hline 0 & Debates em educação & & & & & & & & & & & \\
\hline 0 & Dialogia & & & & & & & & & & & \\
\hline 0 & Dynamis & & & & & & & & & & & \\
\hline 7 & Eccos Revista Científica & 1 & & & & & & & & & & \\
\hline 0 & Educação & & & & & & & & & & & \\
\hline 0 & Educação (Santa Maria. Online) & & & & & & & & & & & \\
\hline 8 & Educa - Revista Multidisciplinar Em Educação & & & & & & & & & & 1 & \\
\hline 0 & Educação e filosofia & & & & & & & & & & & \\
\hline 9 & Educação, Cultura e Sociedade & & & & & & & & & & 1 & \\
\hline 0 & Educação e Realidade & & & & & & & & & & & \\
\hline 0 & Educação em Foco (Juiz De Fora) & & & & & & & & & & & \\
\hline 0 & Educação em perspectiva & & & & & & & & & & & \\
\hline 10 & Educação em Revista (Unesp. Marília) & & & & & & & 1 & & & & \\
\hline 0 & Educação, Sociedade \& Culturas & & & & & & & & & & & \\
\hline 11 & Educação: Teoria e Prática & & & & & 1 & & & & & & \\
\hline 0 & Educação Unisinos & & & & & & & & & & & \\
\hline 0 & Educação por escrito PUCRS & & & & & & & & & & & \\
\hline 0 & Educativa & & & & & & & & & & & \\
\hline 0 & Educere et Educare & & & & & & & & & & & \\
\hline 0 & Em Aberto & & & & & & & & & & & \\
\hline 0 & E- mosaicos revista & & & & & & & & & & & \\
\hline 12 & Ensaio: Pesquisa em Educação em Ciências & & & & 1 & & 1 & & & & & \\
\hline 0 & Ensino de ciências e tecnologia em revista & & & & & & & & & & & \\
\hline 13 & Ensino em Re-vista & & 1 & & & & & 1 & & 1 & & \\
\hline 0 & Ensino \& Pesquisa & & & & & & & & & & & \\
\hline 0 & Espaço pedagógico & & & & & & & & & & & \\
\hline 0 & Exitus & & & & & & & & & & & \\
\hline 14 & Experiências em Ensino de Ciências & & & & & & & & & 1 & & \\
\hline 0 & Formação docente & & & & & & & & & & & \\
\hline 0 & Imagens da Educação & & & & & & & & & & & \\
\hline 0 & Inter-ação (Goiânia) & & & & & & & & & & & \\
\hline 0 & Interfaces científicas - educação & & & & & & & & & & & \\
\hline 15 & Investigações em Ensino de Ciências & & & & & & & & & 2 & & \\
\hline
\end{tabular}




\begin{tabular}{|c|c|c|c|c|c|c|c|c|c|c|c|}
\hline 0 & Linhas (Florianópolis. Online) & & & & & & & & & & \\
\hline 0 & Nuances & & & & & & & & & & \\
\hline 0 & Paradigma (Maracay) & & & & & & & & & & \\
\hline 0 & Pedagogia em Foco & & & & & & & & & & \\
\hline 0 & Percursos (Florianópolis. Online) & & & & & & & & & & \\
\hline 0 & $\begin{array}{l}\text { Perspectivas em Diálogo: revista de Educação e } \\
\text { Sociedade }\end{array}$ & & & & & & & & & & \\
\hline 0 & Práxis Educacional (online) & & & & & & & & & & \\
\hline 16 & Práxis Educativa (UEPG.Online) & & & & & & & & & 1 & \\
\hline 0 & Pro-Posições & & & & & & & & & & \\
\hline 0 & Química Nova na Escola & & & & & & & & & & \\
\hline 17 & Reflexão e ação & & & & & & & & 1 & & \\
\hline 0 & Retratos da Escola & & & & & & & & & & \\
\hline 0 & Revista Brasileira de Educação & & & & & & & & & & \\
\hline 0 & $\begin{array}{l}\text { Revista Brasileira de Ensino de Ciência e } \\
\text { Tecnologia }\end{array}$ & & & & & & & & & & \\
\hline 18 & Revista Brasileira de Ensino de Física & 1 & & & & & & 1 & & & \\
\hline 19 & $\begin{array}{l}\text { Revista Brasileira de Pesquisa em Educação de } \\
\text { Ciências }\end{array}$ & & 1 & & & & & & & & \\
\hline 0 & Revista Brasileira de Ensino de Química & & & & & & & & & & \\
\hline 0 & Revista Brasileira de História da Ciência & & & & & & & & & & \\
\hline 0 & Revista Ciências \& Ideias & & & & & & & & & & \\
\hline 0 & Revista de Ciências da Educação & & & & & & & & & & \\
\hline 0 & Revista Contemporânea de Educação & & & & & & & & & & \\
\hline 0 & $\begin{array}{l}\text { Revista Educação em Rede: Formação e Prática } \\
\text { Docente }\end{array}$ & & & & & & & & & & \\
\hline 20 & $\begin{array}{l}\text { Revista Eletrônica Debates em Educação } \\
\text { Científica e Tecnológica }\end{array}$ & & & & & & 1 & & & & \\
\hline 0 & Revista de Ensino de Bioquímica & & & & & & & & & & \\
\hline 0 & Revista de Educação, Ciências e Matemática & & & & & & & & & & \\
\hline 0 & Revista de Educação Pública & & & & & & & & & & \\
\hline 21 & $\begin{array}{l}\text { Revista de Ensino de Ciências e Matemática } \\
\text { (Rencima) }\end{array}$ & & & & 1 & & & & & & \\
\hline 0 & Revista diálogo Educacional & & & & & & & & & & \\
\hline 0 & Revista diversa prática & & & & & & & & & & \\
\hline 0 & Revista Educação em Questão & & & & & & & & & & \\
\hline 0 & Revista Eletrônica de Educação & & & & & & & & & & \\
\hline 0 & Revista Lusofona de Educação & & & & & & & & & & \\
\hline 0 & Revista Práxis & & & & & & & & & & \\
\hline 22 & Revista tempos e espaços em Educação & & & & & & 1 & & & & \\
\hline 0 & Scientiae Studia (USP) & & & & & & & & & & \\
\hline 0 & Tear - Revista de Educação, Ciência e Tecnologia & & & & & & & & & & \\
\hline 0 & Teoria e Prática da Educação & & & & & & & & & & \\
\hline
\end{tabular}

